This is the author's final, peer-reviewed manuscript as accepted for publication. The publisher-formatted version may be available through the publisher's web site or your institution's library.

\title{
Constructing molecular polygons using halogen bonding and bifurcated $\mathrm{N}$-oxides
}

Christer B. Aakeröy, Tharanga K. Wijethunga, and John Desper

\section{How to cite this manuscript}

If you make reference to this version of the manuscript, use the following information:

Aakeröy, C. B., Wijethunga, T. K., \& Desper, J. (2014). Constructing molecular polygons using halogen bonding and bifurcated N-oxides. Retrieved from http://krex.ksu.edu

\section{Published Version Information}

Citation: Aakeröy, C. B., Wijethunga, T. K., \& Desper, J. (2014). Constructing molecular polygons using halogen bonding and bifurcated N-oxides. CrystEngComm, 16(1), 2831.

Copyright: @ The Royal Society of Chemistry 2014

Digital Object Identifier (DOI): doi:10.1039/c3ce41887a

Publisher's Link:

http://pubs.rsc.org/en/Content/ArticleLanding/2014/CE/c3ce41887a\#!divAbstract

This item was retrieved from the K-State Research Exchange (K-REx), the institutional repository of Kansas State University. K-REx is available at http://krex.ksu.edu 


\title{
Constructing molecular polygons using halogen bonding and bifurcated N-oxides
}

\author{
Christer B. Aakeröy, ${ }^{* a}$ Tharanga K. Wijethunga ${ }^{a}$ and John Desper ${ }^{a}$ \\ Received (in $X X X, X X X$ ) Xth $X X X X X X X X X 20 X X$, Accepted $X$ th $X X X X X X X X X 20 X X$ \\ s DOI: 10.1039/b000000x
}

Bifurcated halogen bonds constructed from $\mathrm{N}$-oxides and complementary halogen-bond donors provide the basis for a synthetic strategy for the deliberate assembly of molecular polygons in the solid state. The donor- and acceptor sites 10 were located on different molecular components and a cocrystallization approach furnished the desired architectures.

$\mathrm{N}$-oxides represent an interesting group of molecules that are highly polar due to the charge separation of the N-O bond. ${ }^{1}$ This molecular feature also leads to their high water solubility ${ }^{2}$ and 15 lipophobicity. ${ }^{3} \mathrm{~N}$-oxides have found applications as ligands in metal coordination complexes ${ }^{4}$ and they have been used as synthetic intermediates, ${ }^{5}$ biologically important compounds, ${ }^{6}$ drugs, ${ }^{7}$ protecting groups, auxiliary agents, photo-active compounds, ${ }^{8}$ oxidants and in catalysis. ${ }^{9}$

20 One of the significant structural characteristic of N-oxides is their ability to form bifurcated non-covalent bonds. ${ }^{10}$ Bifurcation can be defined as the participation of one atom in two different intermolecular interactions, ${ }^{11}$ and this is well known in many hydrogen-bonded systems where the N-oxide oxygen atom is 25 interacting with two different hydrogen-bond donors simultaneously. ${ }^{12}$ An examination of known N-oxide crystal structures with bifurcated bond shows that most of the time the bifurcated angle (donor-O-donor) is close to $120^{\circ}$.

Heteroaromatic N-oxides have shown to interact effectively as 30 electron donors towards perfluorocarbon iodides. ${ }^{13}$ Despite the many similarities between hydrogen bonding and halogen bonding, there are no reports on the deliberate use of bifurcated halogen bonds in combination with $\mathrm{N}$-oxides for directed assembly of supramolecular architectures with predetermined 35 topology and stoichiometries. In principle, such an undertaking should be possible as the halogen bond is mainly electrostatic in nature, and involves an electropositive $\sigma$-hole on a halogen atom and an electron-pair donor. ${ }^{14}$

Many elegant approaches for the synthesis of discrete 40 polygons in the solid state have been presented using coordinatecovalent bonds as the primary synthetic tool, ${ }^{15}$ but relatively few efforts using purely organic building blocks are known. ${ }^{16}$ There are reports where halogen bonds have been used with nitroxides ${ }^{17}$ and ions as halogen bond linkers ${ }^{18}$ for polygon design to some

45 extent. But halogen bonds have not been used in the deliberate construction of well-defined polygons in the solid state, where all interactions are rationalized in a well-defined synthetic strategy.

This journal is (c) The Royal Society of Chemistry [year]
Herein we describe our attempts at synthesizing molecular polygons in the solid state while, at the same point, probing the 50 relative effectiveness of bromo- and iodo-substituted halogenbond donors in practical crystal engineering.

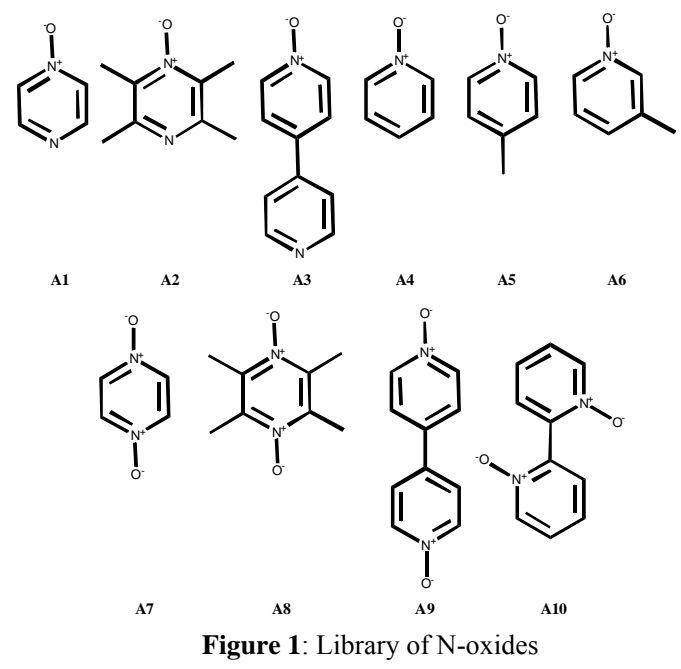

A total of ten N-oxides (A1 - A10) were employed as potential 55 halogen-bond acceptors (six mono N-oxides and four bis-Noxides), Figure 1. The halogen-bond donors were selected such that the relative orientation of their donor sites would offer the appropriate geometric complementarity to the most commonly observed angle in bifurcated $\mathrm{N}$-oxides in order to enable to 60 assembly of the desired polygons.

In order to build a rhomb, we needed a donor molecule with an approximate angle of $60^{\circ}$ between the two donor sites to complement the inherent $\mathrm{X} \cdots \mathrm{O} \cdots \mathrm{X}$ bond angle of $120^{\circ}$ in a bifurcated $\mathrm{N}$-oxide acceptor site as this would complete the 65 overall $360^{\circ}$ requirement, Figure 2 . In order to make a regular hexagon, the donor moieties needed to be positioned at a $120^{\circ}$ angle with respect to each other resulting in a total sum of $720^{\circ}$ for the desired synthetic target, Figure 2. We also postulated that a switch from a monotopic acceptor molecule to a bis-N-oxide, 70 should change the outcome from discrete architectures to chains of polygons, Figure 3.

The synthetic procedure follows well-established solventassisted grinding protocols for co-crystallization reactions. ${ }^{19}$ Each resulting solid was analysed using IR spectroscopy in order 75 to establish if the reaction resulted in a co-crystallization or 
simply a physical mixture of the two reactants (a recrystallization). A total of forty grinding experiments were carried out and the desired outcome was (i) discrete tetrameric rhombi in reactions between 1,2-disubstituted donors and mono $5 \mathrm{~N}$-oxide acceptors; (ii) chains of rhombi when 1,2-disubstituted donors and bis-N-oxides were employed; (iii); discrete hexagons in reactions between 1,3-disubstituted donors and mono $\mathrm{N}$-oxides and (iv) chains of hexagons when the 1,3- halogenated donors were allowed to react with bis-N-oxides, Figure 3. 1,3,5-triiodo10 2,4,6-trifluoro was used instead of 1,3-diiodotetrafluorobenzene due to the fact that former has shown to act similarly to the 1,3diiodo species.

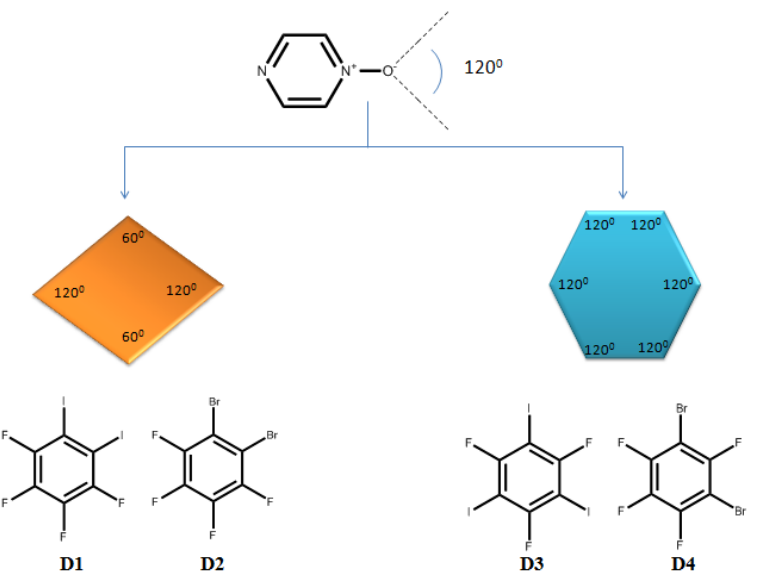

Figure 2: Halogen bond donors and selection rationale

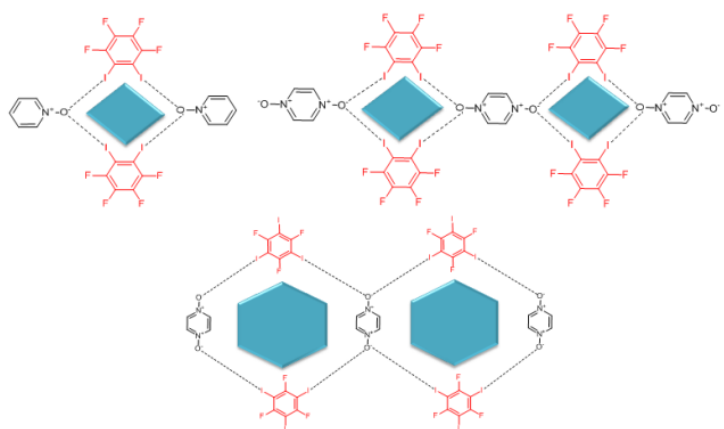

15

Figure 3: Synthetic strategy

All in all, 13 of the 40 experiments provided unambiguous IR spectroscopic evidence for co-crystal formation, resulting in a supramolecular yield of $32.5 \%$ (13/40). None of the bromo20 substituted donors (which are less powerful halogen-bond donors) produced a co-crystal, resulting in an effective success rate for the iodo-based donors of $65 \%(13 / 20)$. Once a cocrystalline phase had been obtained, we attempted to grow crystals for single-crystal diffraction (a total of five structures ${ }_{25}$ were obtained); A4:D3, A5:D1, A8:D1, A6:D1 and A8:D3.

The structure determination of A4:D3 established that the Noxide was bifurcated (with an I-O-I angle of $117^{\circ}$ ) but instead of the desired discrete hexagon, an infinite polymer appeared, Figure 4. The formation of a polymer is always a possibility and 30 on this occasion our synthesis failed to meet the target.

The crystal structure of A5:D1 also shows bifurcation at the Noxide moiety, this time with an I-O-I angle smaller than expected at $93^{\circ}$. Whether this small angle is preventing the formation of a rhomb, or is the result of other interactions is impossible to 35 determine but, either way, a halogen-bonded chain is formed instead of the desired discrete polygon, Figure 5.

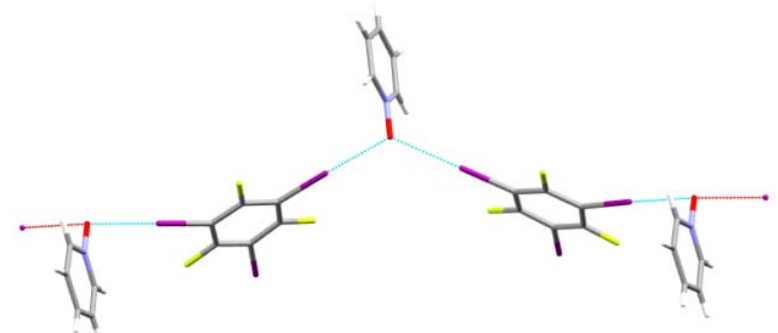

Figure 4: Bifurcated halogen bonds in A4:D3

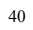

45

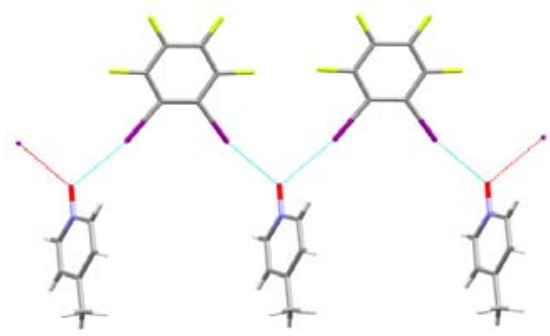

Figure 5: Bifurcated halogen-bonded chains in A5:D1

50 The crystal structure of A8:D1 contains two crystallographically unique $\mathrm{N}$-oxides, one with bifurcated halogen bonds and the other with a single halogen bond, Figure 6 .

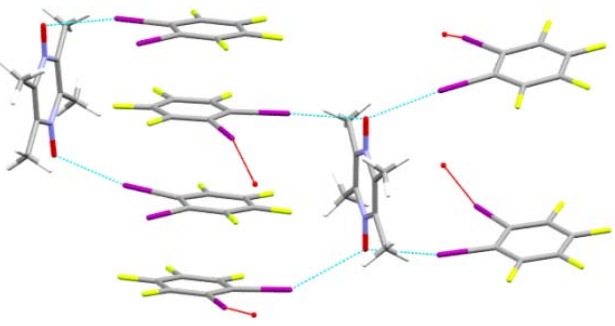

Figure 6: Columnar stacking in the crystal structure of A8:D1

55 The N-oxide entities with single halogen bonds interact with a nearby hydrogen atom forming a bifurcated hydrogen- and halogen bond combination with an angle of $88^{\circ}$. N-oxide entities with bifurcated halogen bonds have an I-O-I angle of $153^{\circ}$ resulting in a chain of polygons albeit not with the intended 60 topology and relative orientation of building blocks, Figure 7 . Neighbouring halogen-bond donors are stacked into columns with a distance of $0.337 \mathrm{~nm}$ hence stabilized by $\pi-\pi$ interactions, ${ }^{20}$ Figure 6.

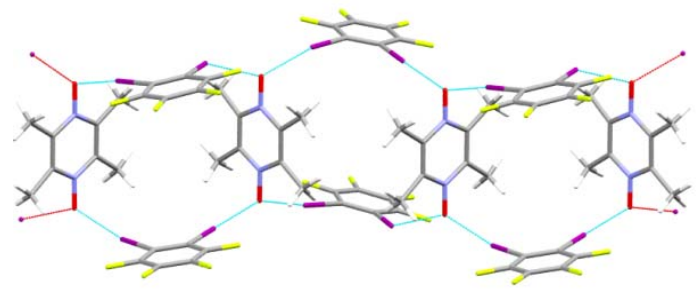

Figure 7: A chain of polygons in the crystal structure of A8:D1 
The first successful supramolecular synthesis in this study was realized in the crystal structure of A6:D1. Bifurcation at the Noxide (I-O-I, $105^{\circ}$ ) is present, and this time, the result is a discrete 5 tetrameric rhomb, Figure 8.

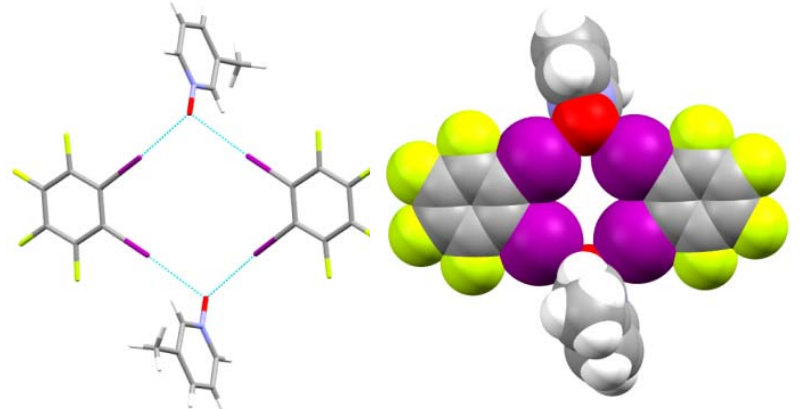

Figure 8: Geometric complementarity leading to a discrete tetrameric rhomb in the crystal structure of A6:D1

${ }_{10}$ The second successful synthesis was achieved with the crystal structure A8:D3. This time, the bifurcated I-O-I angle is close to $120^{\circ}$, and the complementary geometry furnished by the $1,3-$ substituted donor molecule affords the intended chain of hexagonal polygons, Figure 9. Each hexagon offers a small 15 interior 'window' approximately $0.72 \times 0.92 \mathrm{~nm}$, Figure 10.

20

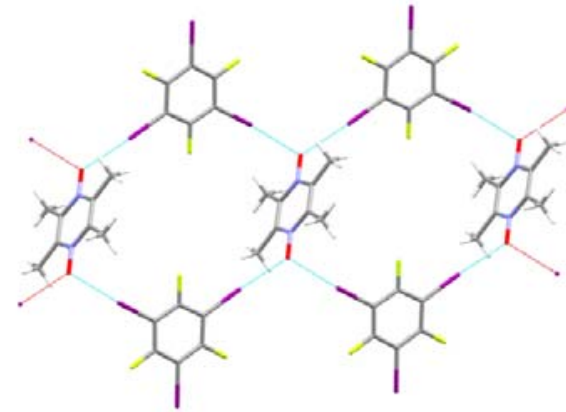

Figure 9: Complementarity of angle and geometry leading to fused hexagons in A8:D3

30

35

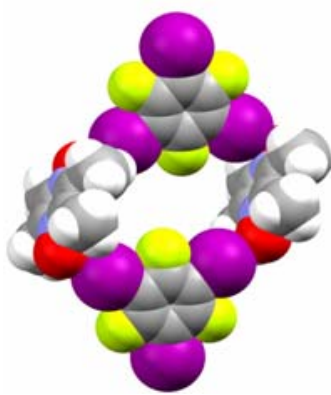

Figure 10: Space filling model of a hexagon in A8:D3

All five co-crystal structures contained the desired bifurcated halogen bond to the $\mathrm{N}$-oxide oxygen atom despite the fact that there have been only a small number of reports describing 45 bifurcated halogen bonds, ${ }^{21}$ (most of which are theoretical studies). ${ }^{22}$ A survey of structures in the CSD produces over 800 hits containing at least one $\mathrm{I} \cdots \mathrm{O}$ halogen bond but less than $5 \%$ of those contain bifurcated bonds, but none of them include $\mathrm{N}$ - oxides as the acceptors even though there are some 30 structures 50 in the CSD involving an N-oxide as a halogen-bond acceptor.

Our results also underscore that large difference in effective halogen-bond strength (for crystal engineering purposes) between iodo- and bromo based halogen-bond donors. The relatively 'hard' oxygen atom preferentially forms halogen bonds with the ${ }_{55}$ 'softer' iodine atom which also underscores that this type of interaction is dominated by electrostatics.

\section{Conclusions}

By using the geometric complementarity of two appropriate molecular building blocks it is possible to build polygons of 60 specific dimensions using the strength and directionality of $\mathrm{I} \cdots \mathrm{O}$ halogen bonds. A key component of the synthetic strategy utilizes the propensity of the N-oxide moiety to form bifurcated intermolecular interactions with $\mathrm{D} \cdots \mathrm{O} \cdots \mathrm{D}$ angles close to $120^{\circ}$.

\section{Notes and references}

${ }_{65}{ }^{a}$ Department of Chemistry, Kansas State University, Manhattan, KS, 66506, USA. E-mail: aakeroy@ksu.edu

$\uparrow$ Electronic supplementary information (ESI) available: Synthesis, characterization, details of the crystallographic work and cif files. See DOI: $10.1039 / \mathrm{b} 000000 \mathrm{x} /$

\section{${ }_{70}$ Notes and references}

${ }^{a}$ Address, Address, Town, Country. Fax: $X X X X X X X X X X$; Tel: $X X X X X X$ XXXX; E-mail: xxxx@aaa.bbb.ccc

$\dagger$ Electronic Supplementary Information (ESI) available: See DOI: $10.1039 / \mathrm{b} 000000 \mathrm{x}$

1 D. Ulku, B.P. Huddle, J.C. Morrow, Acta Cryst. 1971. B27, 432

2 B.Verdejo, G.Gil-Ramirez, P. Ballester, J. Am. Chem. Soc., 2009, 131, 3178

3 M. H. Abraham,L. Honcharova, S. A. Rocco, W. E. Acree, K. M. De Fina, New J. Chem., 2011, 35, 930

4 A.M.Atria, P.Cortes, M.T.Garland, R.Baggio, Acta Cryst. 2003. 59, 967

5 J. P. Freeman, R. C. Grabiak, J. Org. Chem., 1976, 41, 3970; J. P. Freeman, R. C. Grabiak, J. Org. Chem., 1976, 41, 2531; J. P. Freeman, J. A. Kassner, R. C. Grabiak, J. Org. Chem., 1975, 40, 23

6 A. Monge, J. A. Palop, A.L. De Cerain, V. Senador, F. J. MartinezCrespo, Y. Sainz, S. Narro, E. Garcia, C. De Migue1, M. Gonzalez, E. Hamilton, A. J. Barker, E.D. Clarke, D.T. Greenhowl, J. Med. Chem. 1995, 38, 1786

7 S. Chopra, G. A. Koolpe, A. A. Tambo-ong, K. N. Matsuyama, K. J. Ryan, T.B. Tran, R.S. Doppalapudi, E.S. Riccio, L. V. Iyer, C.E. Green, B. Wan, S.G. Franzblau,P.B. Madrid, J. Med. Chem. 2012, 55, 6047

8 A. Albini, M. Alpegiani, Chem. Rev., 1904, 84, 43

9 N. Takenaka, R. S. Sarangthem, B. Captain, Angew.Chem., 2008, 120, 9854

10 CSD ConQuest 1.15, Cambridge Crystallographic Data Centre, U.K., 2012

11 R. Taylor, O. Kennard, W. Versichel, J. Am. Chem. Soc. 1984, 106, 244

12 N.R. Goud, N.J. Babu, A. Nangia, Cryst.Growth Des. 2011,11,1930; N.J. Babu, A. Nangia, L.S. Reddy, Mol.Pharmaceutics , 2007, 4,417; S. K. Koehn,N. L. Tran, S. Gronert, W. Wu, J. Am. Chem. Soc,2010 132, 390

13 M.T. Messina, P Metrangolo, W. Panzeri, T. Pilati, G. Resinati, Tetrahedron, 2001, 57, 8543

14 P. Metrangolo, F. Meyer, T. Pilati, G. Resnati, G. Terraneo, Angew. Chem. Int. Ed. 2008, 47, 6114

15 T. Kawano, J. Kuwana, Chong-Xu Du, I. Ueda, Inorg.Chem., 2002, 41, 4078; K. Kim, Chem. Soc. Rev., 2002, 31, 96

16 C.V.K. Sharma, A. Clearfield, J. Am. Chem. Soc., 2000, 122, 4394 
17 K.J.P. Davy, J. McMurtrie, L. Rintoul, P.V. Bernhardt, A.S. Micallef, CrystEngComm, 2011, 13, 5062

18 M.C. Pfrunder, A.S. Micallef, L. Rintoul, D.P. Arnold, K.J. P. Davy, J. McMurtrie, Cryst. Growth Des., 2012, 12, 714

19 S. L. James, C. J. Adams, C. Bolm, D. Braga, P. Collier, T. Friscic', F. Grepioni, K.D.M. Harris, G. Hyett, W. Jones, A. Krebs, J. Mack, L. Maini, A.G. Orpen, I. P. Parkin, W.C. Shearhouse, J.W. Steed, D.C. Waddell, Chem. Soc. Rev., 2012, 41, 413; C. B. Aakeroy, P.D. Chopade, C. Ganser, A. Rajbanshi, J. Desper, CrystEngComm, 2012, 14, 5845

20 H.W. Roesky, M. Andruh, Coordination Chemistry Reviews, 2003, 236, 91; X. Mei, S. Liu, C. Wolf, Org. Lett., 2007, 9, 2729; J. K. Klosterman, Y. Yamauchi, M. Fujita, Chem. Soc. Rev., 2009, 38, 1714, C. A. Hunter, K. R. Lawsonb, J. Perkinsa, C.J. Urch, J. Chem. Soc., Perkin Trans. 2, 2001, 651

21 B. Ji, W. Wang, D. Deng ,Y. Zhang, Cryst. Growth Des., 2011, 11, 3622

22 A. Bauza, D. Quinonero, A. Frontera, P. M. Deya, Phys. Chem. Chem. Phys., 2011, 13, 20371 